\title{
Tolerated and Unchallenged: Workplace Oppression among Nurses
}

\author{
April Anne Domingo Balanon-Bocato* \\ University of the Cordilleras, Baguio City, Benguet, Philippines
}

*Corresponding author: April Anne Domingo Balanon-Bocato, University of the Cordilleras, Baguio City, Benguet, Philippines, Tel: +63949-991-4021; E-mail: side_a_red@yahoo.com

Received date: December 01, 2017; Accepted date: April 24, 2018; Published date: April 27, 2018

Copyright: (c) 2018 Balanon-Bocato AAD. This is an open-access article distributed under the terms of the Creative Commons Attribution License, which permits unrestricted use, distribution, and reproduction in any medium, provided the original author and source are credited.

\section{Editorial}

The idea that nurses are an oppressed group was first suggested by Roberts in 1983. That the Nursing profession began at a time of patriarchy is something of importance to note. Through the years there has always been a power differential between doctors and nurses. A handful of articles and researches will support the fact that there is indeed a long standing culture of oppression in the nursing profession. Gordon [1], in her book nursing against the odds notes that nurses are viewed essentially as physician subordinates with no real autonomy. It is disturbing to realize that in the health care scenario, some people and some disciplines think that they are more important than others, with this way of thinking; the Dunning-Krueger effect comes to mind. According to this, people display illusory superiority and tend to judge themselves as better than others. Research by Rodwell and Demir in 2012 says that all of us are vulnerable to this decision because we all have pockets of incompetence we do not realize [2]. It isn't a question of ego blinding as to our weaknesses but psychologists have proven that people usually admit their deficits once they can spot them. Ironically, people who have a moderate amount of expertise often have less competence in their abilities; in short, they know enough to know that there is a lot they do not know. Some refer to this as the "bubble of inadequate perception". Further explained, when people are unskilled, they cannot see their own faults-but when they are exceptionally competent, they cannot perceive how unusual their abilities are. Knowing how competent we are and how our skills stack up against other people is more than just a self-esteem boost. It helps us, figure out where we can forge ahead on our own decisions and instincts and when we need to seek advice. But why is there so much self-silencing? If we truly believe that the days when nurses played the role of skilled handmaidens to physicians are in the past, then why do nurses allow their practice to be defined by the physicians they work with? Friere's [3] theory of oppression has been used in nursing literature to define the oppressed state of the nursing profession for years. Whether we would like to admit it or not, the culture of oppression in nursing is something prevailing. Perhaps from a time when the profession of nursing fell under a male dominated group of physicians, or from a time when nurses and doctors belonged to different herds and groups, a time when overt and covert behaviours were used to put people in their place. Researches by Dong and Temple in 2011 [4] have proven that the experience of oppression may result in violence as a way to achieve power over peers. Whenever there is a dominant group and an oppressed group, the dominant group exerts all its power on the oppressed group and because the oppressed group cannot exert their power upward, they unconsciously start attacking each other. Fletcher called this the submissive aggressive syndrome which in nursing has become a perpetuating cycle. How many times have we come across articles describing how "nurses eat their young" in a cycle of unbroken violence? Lateral violence should seem less likely in a field such as nursing where caring and compassion are cornerstones of the job. The shadow of oppression continues to bring with it reluctance to speak up with the fear of being handed powerful disincentives, or the fear of repercussions and drawing attention-causing nurses to hold back on information and insight. A change in behaviour and empowerment become an imperative in and among oppressed groups and in the culture of nursing environments. Like any antecedent to change, the attempt at shifting nurse's attitudes may become the necessary starting point to do away with oppression. Nurses must stop devaluing themselves and push themselves to keep learning. Educators and philosophers have for many years encouraged the advancement of education as a mode of liberation by the oppressed. The more knowledgeable one becomes, the less likely one is to have invisible holes in one's competence. It is high time that nurses start viewing themselves as important and vocally assert themselves as members of a multidisciplinary health team. While it is true that the medical and the nursing professions overlap to a significant extent, nursing is still an autonomous discipline that relies heavily on communication to ensure delivery of efficient care. And the only way to fulfil a nurse's key ethical duty of patient advocacy is to work on espousing a more positive professional identity that would lead to an increase in unity and purpose and that could eventually break the cycle of oppression. Because what's good for one of us is good for each of us, since we all have the right to a safe and supportive work environment and because workplace violence only gains legitimacy when it remains tolerated and unchallenged.

\section{References}

1. Gordon S (2005) Nursing against the odds: How health care cost cutting, media stereotypes, and medical hubris undermine nurses and patient care. Ithaca, NY.

2. Rodwell J, Demir D (2012) Oppression and exposure as differentiating predictors of types of workplace violence for nurses. J Clin Nurs 21: 2296-2305.

3. Freire $P$ (2000) Pedagogy of the oppressed.

4. Dong D, Temple B (2011) Oppression: A concept analysis and implications for nurses and nursing. Nurs Forum 46: 169-176. 